\title{
HYPERSEGMENTED NEUTROPHILS AND MEAN CORPUSCULAR VOLUME IN 100 APPARENTLY HEALTHY VOLUNTEERS WITH ETHANOL ABUSE- AN ANALYSIS
}

\author{
G. S. Thiriveni Balajji ${ }^{1}$, Kalyani A. Nair ${ }^{2}$, C. Lalitha ${ }^{3}$, N. Ravi Shankar 4 , S. Yogalakshmi 5 , S. Usha ${ }^{6}$, L. Madhan7, T. Pavithra ${ }^{8}$ \\ ${ }^{1}$ Associate Professor, Department of Pathology, Government Coimbatore Medical College, CBE. \\ ${ }^{2} 3^{\text {rd }}$ Year MBBS Student, Government Coimbatore Medical College, CBE. \\ 3 Professor and HOD, Department of Pathology, Government Coimbatore Medical College, CBE. \\ ${ }^{4}$ Medical Officer, Master Health Check-up, Government Coimbatore Medical College, CBE. \\ ${ }^{5}$ Senior Assistant Professor, Department of Pathology, Government Coimbatore Medical College, CBE. \\ ${ }^{6}$ Professor, Department of Medicine, Government Coimbatore Medical College, CBE. \\ 7 Professor, Department of Pharmacology, Government Coimbatore Medical College, CBE. \\ ${ }^{8}$ Assistant Professor, Department of Pathology, Government Coimbatore Medical College, CBE.
}

ABSTRACT

\section{BACKGROUND}

Alcohol abuse is one of the reasons for medical and surgical illness in developing and developed countries. Haematological complications related to alcohol are manifold including macrocytic anaemia. The early indicator of anaemia in alcoholic individuals can be detected by monitoring Mean Corpuscular Volume (MCV) and observing peripheral smear for hypersegmented neutrophils.

\section{MATERIALS AND METHODS}

In the present study, we analysed MCV and hypersegmented neutrophils in 100 alcoholics and compared it with 100 non-alcoholic individuals.

\section{RESULTS}

We observed that MCV value was between $95 \mathrm{fL}$ to $99 \mathrm{fL}$ in 60 patients and $100 \mathrm{fL}$ and above in 20 patients. Thus, MCV if observed in alcoholic individuals would warrant nutritional supplements, thereby secondary prevention of macrocytic anaemia would be made possible. Also, hypersegmented neutrophils were present in 67 alcoholic patients while only 11 control population had it in their peripheral smears. This suggests that peripheral smear analysis could be practised routinely in rural centres where higher end equipment is not available. Our results show a significant difference $(p<0.0001)$ in the MCV values and hypersegmented neutrophils between the test and control groups.

\section{CONCLUSION}

Thus, in a low resource setting, analysis for hypersegmented neutrophils in alcoholics and observing MCV values in them would help us predict the onset of macrocytic anaemia at a much early stage and treat them with nutritional supplements.

\section{KEYWORDS}

Alcohol Abuse, Macrocytic anaemia, Mean Corpuscular Volume, Hypersegmented Neutrophil.

HOW TO CITE THIS ARTICLE: Balajji GST, Nair KA, Lalitha C, et al. Hypersegmented neutrophils and mean corpuscular volume in 100 apparently healthy volunteers with ethanol abuse - An analysis. J. Evolution Med. Dent. Sci. 2017;6(50):3832-3837, DOI: $10.14260 /$ Jemds/2017/828

\section{BACKGROUND}

Alcohol abuse is one of the most prevalent social problems existing in developing nations like India. As per the recent WHO reports, about $30 \%$ of the Indian population consume alcohol out of which $4-13 \%$ are daily consumers and up to $50 \%$ of these fall under the category of hazardous drinking. ${ }^{11]}$ Alcohol dependence syndrome has several adverse effects, both direct and indirect, on all the haematological parameters. Alcohol directly influences the precursors of blood cells-RBCs, WBCs and platelets seen in the bone marrow as well as the mature forms seen in blood. The indirect effects are mainly due to metabolic changes caused as a result of nutritional impairment by excessive use of alcohol.,[2]

Financial or Other, Competing Interest: None.

Submission 13-05-2017, Peer Review 11-06-2017,

Acceptance 17-06-2017, Published 22-06-2017.

Corresponding Author:

Dr. G. S. Thiriveni Balajji,

\#806/1058, Sathy Road,

Opp. Textool, Ganapathy, Coimbatore-641006.

E-mail: thirivenib@gmail.com

DOI: $10.14260 /$ jemds $/ 2017 / 828$
The bone marrow abnormalities caused by alcohol is reflected greatly on the RBCs and its precursors. Another feature seen in alcoholics is the deficiency of vitamin B12 and folic acid, which act as maturation factors during the process of erythropoiesis. This leads to the release of immature RBCs called macrocytes, which function less efficiently and produce macrocytic anaemia. Deficiency of the maturation factors also affects the WBCs which can be detected by the presence of hypersegmented neutrophils in the peripheral smear.

Since alcoholism affects at least $30 \%$ of our country's population, it may be estimated that individuals, especially in the productive age group are affected by macrocytic anaemia and have a suppressed immune system. This is one of the major obstacle in the country's overall productivity. If the deficiencies are detected in the earlier stages, treatment can be started quickly and the manifestation of the disease can be prevented. Present study intends to compare the Mean Corpuscular Volume and Hypersegmented neutrophils in 100 alcoholics and 100 non-alcoholics. 


\section{Aim and Objectives}

1. To compare Mean Corpuscular Volume values in $\mathbf{1 0 0}$ apparently healthy volunteers with history of alcoholism and compare it with non-alcoholics.

2. To compare Hypersegmented neutrophils in peripheral smear of 100 apparently healthy volunteers with history of alcoholism and compare with non-alcoholics.

\section{MATERIALS AND METHODS Study Period}

The study was carried out in the Department of Pathology at Coimbatore Medical College and Hospital from May 2016 to July 2016.

\section{Study Population}

After obtaining written, understandable, informed consent, 200 apparently healthy volunteers in the age group of 20-70 years who had come for the master health check-up were chosen as subjects. 100 patients with a history of alcoholism were taken as the test group and 100 patients without alcoholism were taken as the control group.

\section{Exclusion Criteria}

People with history of jaundice, epilepsy, bleeding tendencies, pregnancy, liver and renal diseases were excluded from the study. Only people with normal haemoglobin content for age and sex were considered as subjects. Hypertension and diabetes mellitus were not considered in the exclusion criteria.

\section{Study Design}

The study was a descriptive, comparative retrospective study

\section{Operational Definition}

According to the ICD 10 classification of substance abuse, alcohol dependence syndrome is defined as a cluster of physiological, behavioural and cognitive phenomenon in which the use of alcohol takes on a much higher priority for a given individual than other behaviours that once had a greater value. It is the desire to take alcohol, with the evidence that return to its use after a period of abstinence leads to a more rapid reappearance of other features of the syndrome than that occurring in a non-dependent person.

The definition of hypersegmentation was set at $4 \%$ or more of neutrophils with 5 distinct lobes, connected by filaments or of any number of cells with 6 or more lobes.

According to WHO, anaemia or deficiency is said to exist when the haemoglobin level is below $13 \mathrm{~g} / \mathrm{dL}$ of venous blood in adult males and $12 \mathrm{~g} / \mathrm{dL}$ in adult non-pregnant females.

Mean corpuscular volume is the average volume of the red blood cell and measured directly with automated instruments. [3]

\section{Methodology}

A complete medical history, diet, medication, alcohol and smoking habits were taken from each subject. In addition, a detailed history regarding alcoholism, including age at which consumption started, daily intake of alcohol, years since having stopped, if applicable, was taken.

$2 \mathrm{~mL}$ of blood was collected from each subject in an EDTA container and tested for $\mathrm{Hb}$ and MCV values in a Coulter counter.
Haemoglobin level less than $10 \mathrm{~g} / \mathrm{dL}$ in females and 12 $\mathrm{g} / \mathrm{dL}$ in males was categorised as anaemic. MCV values of more than 100 were taken as macrocytic.

A peripheral smear was made using Leishman's stain and observed for the presence of hypersegmentation in neutrophils.

The data so collected was analysed and statistical analysis of Mean, Median, Mode, Standard deviation, Upper limit values and Lower limit values for MCV values and Hypersegmented neutrophils' values between test group and control group were performed using statistical software program SPSS 17.0 for windows student version. Also $p$ value was compared regarding MCV values and Hypersegmented neutrophils between the test group and control group using Mann-Whitney $U$ test and Chi square test with software program (SPSS 17.0 for windows student version).

\section{RESULTS}

\begin{tabular}{|c|c|c|}
\hline Age & No. of Cases & No. of Controls \\
\hline$<29$ & 5 & 2 \\
\hline $30-39$ & 30 & 34 \\
\hline $40-49$ & 45 & 33 \\
\hline $50-59$ & 15 & 24 \\
\hline$>60$ & 5 & 7 \\
\hline Total & $\mathbf{1 0 0}$ & $\mathbf{1 0 0}$ \\
\hline Table 1. Age Distribution of Alcoholic Individuals and \\
Control Population \\
\hline
\end{tabular}

It was observed that the Mean age in the test group was 42.5 years, Median age was 44 years and Mode was 44 years. The standard deviation in the test group was $42.5 \pm 9.07$ with the upper limit of age being 51.57 years and lower limit being 33.43 years.

The Mean age in the control group was 44.13 years, Median age was 43 years and Mode was 37 years. The standard deviation in the control group was $44.13 \pm 9.15$ with upper limit being 53.28 years and lower limit being 34.98 years.

\begin{tabular}{|c|c|c|}
\hline Gender & Cases & Controls \\
\hline Male & 58 & 53 \\
\hline Female & 42 & 47 \\
\hline Total & $\mathbf{1 0 0}$ & $\mathbf{1 0 0}$ \\
\hline \multicolumn{2}{|c|}{ Table 2. Gender Distribution of Cases and Control } \\
Population
\end{tabular}

It was observed that alcohol abuse was more in male patients (58\%) than in female patients $(42 \%)$.

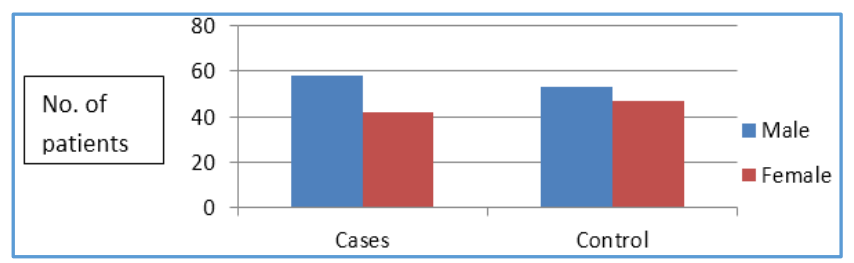

Figure 1. Gender Distribution among Case and Control Groups 


\begin{tabular}{|c|c|c|c|c|}
\hline Group & MCV & Cases & Control & Total \\
\hline 1 & $<79$ & 0 & 3 & 3 \\
\hline 2 & $80-89$ & 0 & 90 & 90 \\
\hline 3 & $90-94$ & 20 & 4 & 24 \\
\hline 4 & $95-99$ & 60 & 3 & 63 \\
\hline 5 & $100-110$ & 20 & 0 & 20 \\
\hline & TOTAL & 100 & 100 & 200 \\
\hline
\end{tabular}

Table 3. MCV Distribution in Cases and Control Population

The Mean MCV value in the test group was $98.4 \mathrm{fL}$, Median was $98 \mathrm{fL}$ and Mode was $94.5 \mathrm{fL}$. The standard deviation was observed to be $98.4 \pm 4.2 \mathrm{fL}$ with upper limit being 102.6 fL and lower limit being $94.2 \mathrm{fL}$.

The Mean MCV value in the control group was $85.2 \mathrm{fL}$, Median was $84.9 \mathrm{fL}$ and Mode was $81.3 \mathrm{fL}$. The standard deviation was observed to be $85.2 \pm 3.7 \mathrm{fL}$ with upper limit being $88.9 \mathrm{fL}$ and lower limit being $81.5 \mathrm{fl}$.

For the above Table 3, Chi square test was done. The value obtained was 99.6. From the Chi square table, the value is highly significant for the degree of freedom 4 . Hence, MCV changes and alcoholism habit are related. The patients with alcoholism have elevated MCV values. Thus, followup of MCV value in alcoholic patients would help in early detection of macrocytic anaemia and the need for nutritional supplementation as therapy can be considered in alcoholic patients.

It was observed that $60(60 \%)$ alcohol abuse patients had MCV in the range between 95 to $99 \mathrm{fL}$. Also, MCV was above $100 \mathrm{fL}$ in 20 (20\%) alcohol abuse patients. Whereas, in the control population MCV was 95 to $99 \mathrm{fL}$ in only $3(3 \%)$ patients and was not above $100 \mathrm{fL}$ in any control patients. For the experimental series involving MCV, data are presented as mean \pm 10 . Statistical significance was estimated for each variable using Mann-Whitney $U$ test using a software program (SPSS 17.0 for windows student version).

MCV values were compared between the control subjects and test subjects. Our results show a significant difference ( $p$ $<0.0001$ ) in the MCV values between the two. This implies that MCV values are increased significantly especially in the 95 to $99 \mathrm{fL}$ range in patients with alcoholism than patients without alcoholism habit. Hence, eliciting the history of alcoholism in borderline elevated MCV values (95 - $99 \mathrm{fL}$ ) would help in prescribing nutritional supplementation to prevent macrocytic anaemia in such patients.

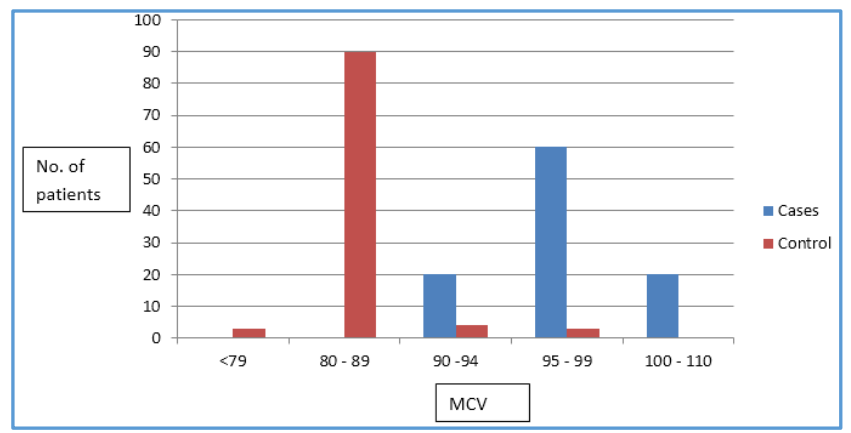

Figure 2. MCV Distribution in Cases and Control Population

\begin{tabular}{|c|c|c|c|}
\hline HSN & Cases & Control & Total \\
\hline Present & 67 & 11 & 78 \\
\hline Absent & 33 & 89 & 122 \\
\hline Total & $\mathbf{1 0 0}$ & $\mathbf{1 0 0}$ & $\mathbf{2 0 0}$ \\
\hline \multicolumn{4}{|c|}{ Table 4. Hypersegmented Neutrophil in Cases } \\
and Control Population \\
\hline
\end{tabular}

For the above Table 4, Chi square test was calculated. The value of Chi square is 60.28 . From the Chi square table, the value is significant for the degree of freedom 1 . The critical value is highly significant, hence the presence of hypersegmented neutrophils and patients with alcoholism habit are related. Patients with alcoholism tend to have more hypersegmented neutrophil than control patients without alcoholism. Thus, occurrence of hypersegmented neutrophil in peripheral smear of alcoholism patient would help in detecting onset of macrocytic anaemia in a low resource setting. Hence, eliciting the history of alcoholism would be important in such patients and early nutritional supplementation as therapy would aid in secondary prevention of macrocytic anaemia in patients with alcoholism.

Hypersegmented neutrophils were observed in 67 (67\%) alcohol abuse patients while only $11(11 \%)$ control patients had hypersegmented neutrophils in peripheral smear. For the data involving hypersegmented neutrophils, it was presented as mean \pm 10 . Statistical significance was estimated using Mann-Whitney $U$ test using a software program (SPSS 17.0 for windows student version). Presence and absence of hypersegmented neutrophils were compared between the control subjects and test subjects. Our results show a significant difference $(\mathrm{p}<0.0001)$ in the hypersegmented neutrophils between the two. Thus, hypersegmented neutrophils are present in patients with alcoholism habit than those without alcoholism. Hence, detection of hypersegmented neutrophil in alcoholic patients would aid in appropriate nutritional supplementation to prevent macrocytic anaemia in such patients.

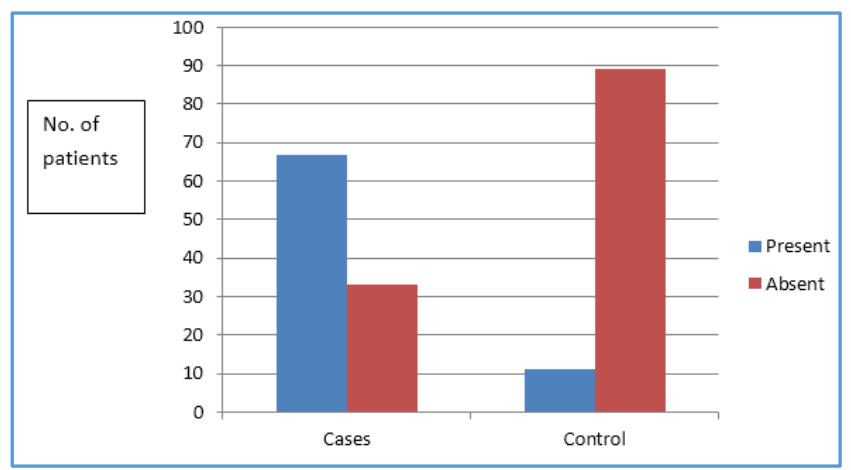

Figure 3. Hypersegmented Neutrophil in Cases and Control Population

\section{DISCUSSION}

Alcohol consumption leads to many adverse effects in metabolism, especially affecting blood cells and their functions, both directly and indirectly.

Alcohol has a direct toxic effect on RBC membrane.[2] Indirect effects on alcohol consumption is secondary to nutritional deficiency, particularly that involving vitamin B12 
and folic acid. Both direct and indirect effects lead to macrocytosis.

Macrocytosis refers to a condition in which red blood cells are larger than normal. It is evaluated by measuring mean corpuscular volume. Normal MCV ranges from 80-100 femtolitres and varies with age and reference laboratory.[4]

MCV = haematocrit\%/RBC count in 106/microlitre.

Macrocytosis is a common finding with a prevalence estimating from $1.7 \%$ to $3.6 \%$. $[5,6,7]$

The significance of macrocytosis has been underestimated by medical professionals because about $60 \%$ of the patients present without associated anaemia[ ${ }^{[8]}$ when there are other abnormal features to be noted.

\section{Macrocytosis without anaemia is observed in the} following Conditions-

A) RBCs of newborns and infants are usually larger than that of normal adult RBCs with a mean MCV of $108 \mathrm{fL}$.[9]

B) Pregnancy.

C) Normal variant of a genetic predisposition found in other family members, requiring no further therapeutic intervention.[10.11]

Spurious elevation of MCV occurs in hyperglycaemia, presence of cold agglutinin, leucocytosis, reticulocytosis, delayed sample processing[9,10] and partial occlusion of the aperture.[12, 13]

Macrocytosis with associated anaemia could be due to megaloblastic or non-megaloblastic causes, based on bone marrow examination findings.

\section{The following may be Categorised as Common Pathologic} Causes of Macrocytosis[14]

1. Drugs.

2. Alcoholism.

3. Reticulocytosis.

4. Non-alcoholic and alcoholic lover disease.

5. Hypothyroidism.

6. Vitamin B12 deficiency.

7. Folate deficiency.

8. Multiple myeloma.

9. Myelodysplastic syndromes.

10. Aplastic anaemia.

11. Acute leukaemia.

\begin{tabular}{|c|c|c|c|}
\hline $\begin{array}{c}\text { Sl. } \\
\text { No. }\end{array}$ & Author & $\begin{array}{c}\text { Number of } \\
\text { Patients } \\
\text { in the study }\end{array}$ & $\begin{array}{c}\text { Cause of } \\
\text { Macrocytic anaemia }\end{array}$ \\
\hline 1. & Savage et al[13] & 300 & $\begin{array}{c}\text { Drug therapy and } \\
\text { alcohol abuse was the } \\
\text { most frequent cause. } \\
\text { Vitamin B12 and folate } \\
\text { deficiency induced was } \\
\text { rare }\end{array}$ \\
\hline 2. & Keenan et al[14] & & $\begin{array}{c}\text { Alcoholism was the } \\
\text { most common cause } \\
\text { followed by } \\
\text { haematological } \\
\text { disorders. Study } \\
\text { excluded drug-induced }\end{array}$ \\
\hline
\end{tabular}

\begin{tabular}{|c|c|c|c|}
\hline & & causes. & Mahmoud et \\
al[15] & $\begin{array}{c}\text { 124 patients } \\
\text { in the age } \\
\text { group } \geq 75 \\
\text { years }\end{array}$ & $\begin{array}{c}\text { Haematological and } \\
\text { malignancy were } \\
\text { associated with } \\
\text { macrocytosis }\end{array}$ \\
\hline 4. & $\begin{array}{c}\text { Breedveld et al,[6] } \\
\text { Seppa et al[16] }\end{array}$ & & $\begin{array}{c}\text { Vitamin deficiency and } \\
\text { alcoholism were most } \\
\text { common causes }\end{array}$ \\
\hline
\end{tabular}

Drugs Causing Macrocytosis include the following[14]

A) Chemotherapeutic agents.
a) Cyclophosphamide.
b) Hydroxyurea.
c) Methotrexate.
d) Azathioprine.
e) Mercaptopurine.
f) Cytosine arabinoside.
g) 5-fluorouracil.

B) Antiretroviral drugs.

a) Zidovudine.

C) Antimicrobial agents-
a) Pyrimethamine.
b) Sulphamethoxazole.
c) Trimethoprim.
d) Valacyclovir.

D) Diuretics.
a) Triamterene.

E) Anticonvulsant drugs.

a) Phenytoin.

Macrocytosis is the earliest indication seen in complete blood counts of patients with vitamin B12 or folate deficiency. ${ }^{[14]}$

In vitamin B12 and/or folate deficiency, there is a defect in nuclear maturation which lags behind cytoplasmic maturation resulting in larger than normal blood cells. Macrocytosis in alcoholism is multivariate involving direct toxic effect on the RBC membrane, associated chronic liver disease and nutritional deficiency due to faulty dietary habits.

According to Edward R Eicher.[17] evolution of anaemia in an alcoholic patient proceeds through the following stages with various time intervals between the studies-

1. Negative vitamin balance: This is the stage at which the patient reduces his dietary intake and ingests moderate amount of alcohol. In this stage, there is a sharp fall in folic acid levels, with no abnormal erythropoiesis.

2. Megaloblastic conversion: This occurs as early as one week after beginning alcohol consumption.

3. Sideroblastic anaemia: This occurs soon after the megaloblastic change and appears to be related to either pyridoxine deficiency or an intracellular enzyme defect.

4. Early resolution: This is the recovery stage in which there is rapid disappearance of megaloblastic change with persistence of sideroblasts. 
5. Late resolution: In this stage, there is marrow erythroid hyperplasia and reticulocytosis suggesting haemolytic condition.

Owing to the above factors, differences in the timing of the medical evolution rather than aetiology leads to any of the mentioned patterns in an alcohol-dependent patient.

\section{Macrocytosis can be Identified by Two Methods-}

- Automated counters.

- Peripheral blood smear.

In automated counters, MCV represents the mean of the distribution curve and is insensitive to the presence of number of macrocytes.[14] Also it must be noted that MCV is an average value and it can be affected by a coexisting microcytic anaemia including iron deficiency anaemia, anaemia of chronic illness and thalassemia trait.

Thus, compared to peripheral smear, MCV may underestimate more than $30 \%$ of the cases.[15]. In peripheral smear examinations, the presence of macro-ovalocytes with MCV more than $115 \mathrm{fL}$ and hypersegmented neutrophils, along with anisocytosis and poikilocytosis affects a megaloblastic disorder associated with B12 or folate deficiency. Round macrocytes occur in anaemia associated with chronic illness while round target appearing macrocytes are characteristic of liver diseases such as hepatitis, obstructive jaundice and acute and chronic alcoholism related liver diseases.[14]

In the present study, it was observed that $60(60 \%)$ alcohol abuse patients had MCV in the range between 95 to $99 \mathrm{fL}$. Also, MCV was above $100 \mathrm{fL}$ in 20 (20\%) alcohol abuse patients. Whereas in the control population, MCV was 95 to $99 \mathrm{fL}$ in only $3(3 \%)$ patients and was not above $100 \mathrm{fL}$ in any control patients. MCV values were compared between the control subjects and test subjects. Our results show a significant difference $(p<0.0001)$ in the MCV values between the two. Thus, indicating that followup of MCV values in alcoholic patients would detect the moderate increase in MCV value i.e. in the range of 95 to $99 \mathrm{fL}$ even before the onset of full blown macrocytic anaemia. Thus, supplementation of Vitamin B12 and folic acid in alcoholic patients with MCV between 95 to $99 \mathrm{fL}$ would prevent macrocytic anaemia in these patients.

\section{Discussion on Hypersegmented Neutrophils}

Neutrophils are the most abundant type of granulocytes and most abundant type of WBCs. They form an essential part of the innate immune system. Their main role is in phagocytosis.

Neutrophils are formed by the process of haemopoiesis in bone marrow. Vitamin B12 and folic acid is essential for maturation and DNA synthesis of neutrophils. A typical neutrophil consists of a neutral pink coloured cytoplasm and a multilobed nucleus. The number of lobes varies from 3-5 in normal conditions. The lobes are connected by chromatin. The average lifespan of an inactivated neutrophil in circulation is between 5 and 90 hours. As a neutrophil matures, the number of segments in the nucleus increases. If, in the peripheral smear, more than $10 \%$ of the neutrophils have 5 or more lobes, then the neutrophils can be considered to be hypersegmented.[18] Hypersegmentation was set at $4 \%$ or more of neutrophils with 5 distinct lobes, connected by filaments or of any number of cells with 6 or more lobes.

Hypersegmentation of neutrophils are mainly seen due to megaloblastic anaemia, where there is deficiency of vitamin B12 and folic acid. Since alcohol intake can cause deficiency of either of these, alcoholism is strongly associated with incidence of hypersegmented neutrophils.

In addition to causing maturation defects, alcohol consumption also leads to a number of other changes related to neutrophils such as neutropenia, neutrophil delivery or the ability of the cell to reach sites of inflammation as well as decreased ability to adhere to endothelium as a result of either reduced production of leukotrienes or the inability to respond to leukotrienes. ${ }^{[2]}$

In case of vitamin B12 deficiency or folate deficiency related megaloblastic anaemia, the MCV of erythrocytes is also seen to be raised. Hypersegmented neutrophils and high MCV generally occur hand in hand. But several studies have reported that one of the earliest indicators of megaloblastic change is hypersegmented neutrophils rather than raised MCV. Hence, in many cases, where anaemia and raised MCV have not manifested, hypersegmented neutrophils can be reported.

According to Thompson et al, in $91 \%$ of 515 patients, hypersegmented neutrophil was a more sensitive indicator as compared to MCV.[19]

In the present study, hypersegmented neutrophils were observed in 67 (67\%) alcohol abuse patients while only 11 (11\%) control patients had hypersegmented neutrophils in peripheral smear. Presence and absence of hypersegmented neutrophils were compared between the control subjects and test subjects. Our results show a significant difference $(\mathrm{p}<$ 0.0001 ) in the hypersegmented neutrophils between the two. Hence, in rural areas where higher end equipment is not available, a simple peripheral smear staining would help in identification of hypersegmented neutrophil in alcoholic patients. This would help in supplementation of vitamin B12 and folic acid in alcoholic patients with hypersegmented neutrophil to prevent macrocytic anaemia in such patients.

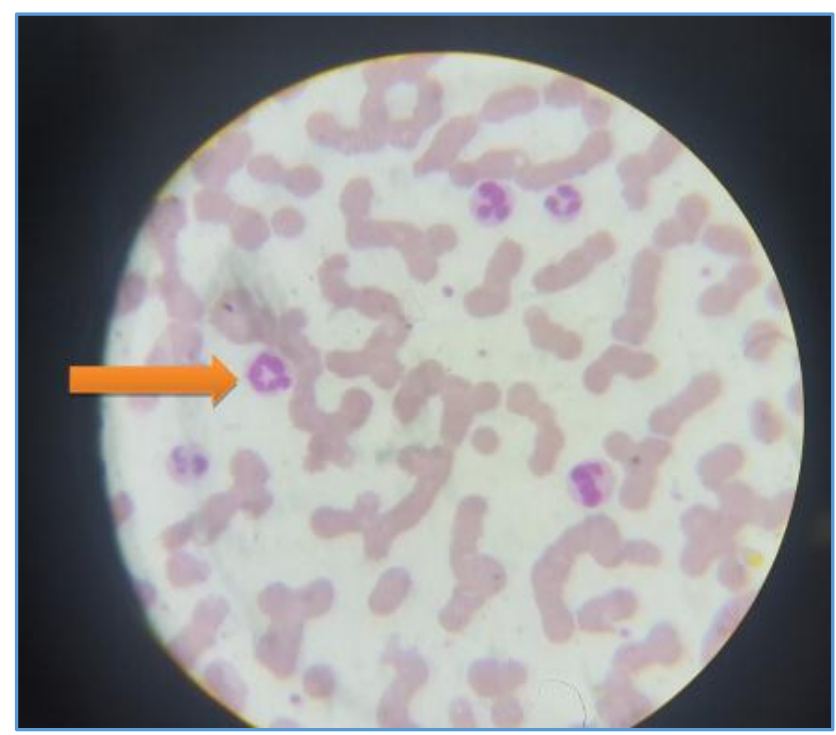

Figure 4. Oil Immersion View of Hypersegmented Neutrophil in Peripheral Smear (Leishman Stain $100 \times 10 X$ ) 


\section{CONCLUSION}

Chronic alcoholism is very common in our country and there is very high risk for macrocytic anaemia which affects the individual's overall productivity. According to the present study, there is significant difference ( $p<0.0001)$ between alcoholic and non-alcoholic patients regarding the presence of hypersegmented neutrophils and changes in MCV value. This can indicate the toxic effects of alcohol on developing blood cells. The direct estimation of vitamin B12 and folic acid is an extremely expensive procedure that is not easily available in the rural areas, where the problem of alcoholism is more prevalent. Highly elevated MCV values in alcoholic subjects in routine haemogram signifies that followup of MCV values in alcoholic individuals might aid in early therapy with vitamin B12 and folic acid and help in secondary prevention of macrocytic anaemia. Detection of hypersegmented neutrophils in the peripheral smear can be performed in low resource settings and it aids in the early detection of impending folate and vitamin B12 deficiency. And hence, with routine haemogram and peripheral smear staining in alcoholic individuals, impending macrocytic anaemia can be prevented by supplementing the susceptible individuals with vitamin B12 and folic acid therapy.

\section{ACKNOWLEDGEMENTS}

We gratefully acknowledge the administrative support of Dean Dr. A. Edwin Joe, M.D., B.L.; Dr. R. Mani, Vice Principal and Professor of Pharmacology; and Dr. D. Nalini Ph.D., Multidisciplinary Research Unit, Government Coimbatore Medical College, Coimbatore towards conducting this research project.

\section{REFERENCES}

[1] WHO 2014. Global status report on alcohol and health, WHO library cataloguing in- publication data, Geneva 2014.

[2] Ballard HS. Haematological complications of alcoholism. Alcoholism: Clinical and experimental Research 1989;13(5):706-20.

[3] Bessman JD, Gilmer PR, Gardner FH. Improved classification of anemias by MCV and RDW. Am J Clin Pathol 1983;80(3):322-6.

[4] Chanarin I, Metz J. Diagnosis of cobalamine deficiency: the old and new. Br J Haematology 1997;97(4):695-700.
[5] Davidson RJ, Hamilton PJ. High mean red cell volume: its incidence and significance in routine haematology. J Clin pathology 1978;31(5):493-8.

[6] Breedveld FC, Bieger R, Van Wermeskerken RK. The clinical significance of macrocytosis. Acta Med Scand 1981;209(4):319-22.

[7] Colon-Otero G, Menke D, Hook CC. A practical approach to differential diagnosis and evaluation of the adult patient with macrocytic anemia. Med Clin North Am 1992;76(3):581-97.

[8] Nathan DG, Orkin SH, Hook AT, et al. Nathan and Oski's hematology of infancy and childhood. $6^{\text {th }}$ edn. Philadelphia: Saunders 2003:1841.

[9] Hoffbrand V, Provan D. ABC of clinical haematology. Macrocytic anaemias. BMJ 1997;314(7078):430-3.

[10] Sechi LA, De Carli S, Catena C, et al. Benign familial macrocytosis. Clinical lab haematol 1996;18(1):41-3.

[11] Aslinia F, Mazza JJ, Yale SH. Megaloblastic anemia and other causes of macrocytosis. Clin Med Res 2006;4(3):236-41.

[12] Sarma RP. Red cell indices. In: Walker HK, Hall WD, Wurst JW, (eds). Clinical methods: the history physical and laboratory examinations. Boston: Butterworths 1990:720-3.

[13] Savage DG, Ogundipe A, Allen RH, et al. Etiology and diagnostic evaluation of macrocytosis. Am J Med Sci 2000;319(6):343-52.

[14] Keenan WF. Macrocytosis as an indicator of human disease. J Am Board fampract 1989;2(4):252-6.

[15] Mahmoud MY, Lugon M, Anderson CC. Unexplained macrocytosis in elderly patients. Age ageing 1996;25:310-2.

[16] Seppa K, Heinila K, Sillanaukee P, et al. Evaluation of macrocytosis by general practitioners. J Stud Alcohol 1906;57(1):97-100.

[17] Eichner ER, Hillman RS. The evolution of anemia in alcoholic patients. American journal of medicine 1971;50(2):218-32.

[18] Gulati G. Blood cell morphology grading guide. American Society of Clinical Pathology 2009:62-3.

[19] Thompson WG, Cassino C, Babitz L, et al. Hypersegmented neutrophils and vitamin B12 deficiency. Hypersegmentation in B12 deficiency. Acta Haematol 1989;81(4):186-91. 